\title{
Proliferation of Human Mesenchymal Stem Cells Derived from Adipose Tissue on Polyurethanes with Tunable Biodegradability
}

\author{
laci M. Pereira \\ Laboratório de Materiais, Divisão Bélica, Centro Tecnológico do Exército \\ Viviane Gomide, Rodrigo L. Oréfice \\ Departamento de Engenharia Metalúrgica e de Materiais, UFMG
}

Maria de F. Leite

Departamento de Fisiologia e Biofísica, UFMG

Alessandra A. C. Zonari, Alfredo de M. Goes

Departamento de Bioquímica e Imunologia, UFMG

\begin{abstract}
Polyurethanes (PUs) have been considered good candidates to be used in biomedical temporary devices that require mechanical properties comparable to soft tissues. However, toxicity of some PUs is still a concern, since these polyurethanes can contain potential toxic components and residual organic solvents derived from their synthesis. In this work, in vitro tests to measure viability and proliferation of human mesenchymal stem cells (hMSCs) in contact with PUs with tunable biodegradability were performed by employing MTT, alkaline phosphatase and collagen secretion assays. PUs were produced in an aqueous environment by employing isophorone diisocyanate/ hydrazine (hard segment) and poly(caprolactone diol)/2,2-bis (hydroxymethyl) propionic acid (soft segment) as the main reagents. Three series of PUs having different soft segment contents were synthesized. These PUs had their chemical structure, morphology and hydrolytic degradation investigated. The rate of hydrolysis of the obtained PUs was tailored by modifying the soft segment content of the polymers. In vitro results showed that PUs can provide a satisfactory environment for the adhesion and proliferation of hMSCs.
\end{abstract}

Keywords: Polyurethane, articular cartilage, biodegradation, in-vitro degradation, mesenchymal stem cells.

\section{Introduction}

Normal pain-free movement depends on the unique properties of the articular cartilage that forms the bearing surface of synovial joints. However, articular cartilage has a poor intrinsic capacity for repair. Even a small defect caused by mechanical damage will fail to heal and degenerate over time progressing to the debilitating condition of osteoarthritis ${ }^{[1,2]}$. Currently, at an experimental stage, the strategies of tissue engineering are been investigated for the repair of articular cartilage defects.

Tissue engineering is a cross disciplinary field that combines biochemistry, cells, biomedical engineering and materials science to improve or replace biological functions. In the first step of one of the tissue engineering approach, cells are seeded in vitro on bioresorbable scaffolds in a bioreactor to construct a new tissue which will be implanted in vivo to recover the normal tissue function ${ }^{[3]}$. As the scaffolds play an important role in the formation of new articular surfaces, they should stabilize the growth factors and/or cells in the defect. Moreover, ideal scaffolds are designed to be biocompatible and bioabsorbable. Because the cartilage surface is responsible to dampen and to distribute loads within the cartilage and to the sub chondral bone during a large number of cycles, to increase the chances that the reparative process will be successful, the designed scaffold should match mechanical characteristics to form a new articular cartilage as tissue ${ }^{[1,2,4,5]}$. Nowadays, a variety of materials, including PUs are been investigated as potential candidates for restoration of an articular surface. PUs are one of the most important families of polymers. A typical PU may contain, in addition to the urethane linkages, aliphatic and aromatic hydrocarbons, esters, ethers, amides, urea, and isocyanurates groups ${ }^{[6]}$. PUs are known to have special properties such as 1) easy preparation method; 2) high resistance to solvents; 3) long-term stability against exposure to sunlight; and 4) consistent elastic properties $^{[7,8]}$. Among all the types of polyurethanes available, segmented PUs have received considerable attention since they can be suitable candidates to participate in biomedical applications such as: insulators for cardiac pacing leads, blood bags, intra-aortic balloons, ventricular assist devices, vascular prostheses, catheters, surgical drapes, breast implant coatings, skin wound dressings, gastric balloons, and tissue adhesives ${ }^{[9]}$. However, PUs are still considered potentially toxic for the body, since they are usually produced using aromatic diisocyanates and organic toxic solvents ${ }^{[10]}$.

Transplantation of human mesenchymal stem cells (hMSCs) that are capable of differentiation into cells of the chondrogenic lineage has opened new potential therapeutic approaches for the repair of articular cartilage defects ${ }^{[11]}$. MSCs are multipotent stem cells that have the ability to self-renew and intrinsically repair and regenerate damaged tissues. In addition, MSCs have the capacity to differentiate into a variety of other connective tissues such cartilage, bone, tendon, adipose tissue and muscle ${ }^{[1]}$. The multilineage potential of MSCs from the bone marrow stroma has been characterized extensively. However, the clinical use of MSCs has presented problems, including pain, morbidity, and low cell number upon harvest. An alternative sources for MSCs is the use of human adipose derived adult stem (hADAS) cells which represents a feasible approach to many of these issues ${ }^{[11,12]}$. 
In this work, PUs with adjustable biodegradability for cartilage tissue engineering were synthesized using water as main component for the reaction environment. The obtained waterborne PUs had their biodegradable behavior and morphology studied and were tested in vitro to check the degree of toxicity of the materials when exposed to hMSCs derived from adipose tissue.

\section{Experimental}

\section{Prepolymer synthesis}

Poly(caprolactone diol) (PCL - Mn = 1250, 2000 g.mol ${ }^{-1}$ ), isophorone diisocyanate (IPDI), 2,2-bis(hydroxymethyl), propionic acid (DMPA) and dibutyl tin dilaurate (DBDLT) were obtained from Aldrich (St. Louis, MO). Triethylamine (TEA, 98\%) and hydrazine (HZ, 25\%) were purchased from Vetec (RJ, Brazil). All these chemicals were employed throughout this work without any previous treatment.

PUs were prepared by the prepolymer mixing method, using a $250 \mathrm{~mL}$ three neck glass flask equipped with a heating mantel, a mechanical stirrer, a thermometer, under nitrogen atmosphere. The PCL and DMPA were stirred in the glass reactor at $60{ }^{\circ} \mathrm{C}$ for 30 minutes. IPDI was added to the reactor in the presence of DBDLT ( $\mathrm{NCO} / \mathrm{OH}$ ratio of 2) under $\mathrm{N}_{2}$ atmosphere. The reaction was carried out at $70-75^{\circ} \mathrm{C}$ for 3 hours. After cooling the prepolymer down to $40{ }^{\circ} \mathrm{C}$, the carboxylic acid groups were neutralized by the addition of TEA. The mixture was then gentle stirred for 40 minutes. The dispersion in water and PU chain extension were obtained by adding $\mathrm{HZ}$ and deionized water to the neutralized prepolymer under high-speed stirring. To ensure that the reaction was completed, the mixture was stirred for 30 minutes. This chemical procedure was successful in producing PUs water dispersions with solid content about $30 \%$ (PUs). The feed ratios are shown in Table 1, where $W(S S)$ is weight fraction of soft segment content, obtained according to Equation 1.

$$
W(S S)(\%)=\frac{\text { Weight }_{P C L}+\text { Weight }_{D M P A}}{\text { Weight }_{P U}} \times 100
$$

\section{Hydrolytic degradation tests}

Hydrolytic degradation tests were carried out by weighing dried samples having $10 \mathrm{~mm}$ in diameter and $1 \mathrm{~mm}$ thick and immersing them in two different media: $\mathrm{pH} 7.4$ phosphate buffered solution (PBS) and $\mathrm{NaOH} 3 \mathrm{wt} \%$ aqueous solution. Examination in alkaline solution was performed to study accelerated degradation process. The samples were removed from the media at predetermined time intervals, rinsed three times with distilled water, and immersed in distilled water for 1 hour. This last step aimed to remove the ions absorbed by the polymers. The specimens were then dried to a constant weight at $37^{\circ} \mathrm{C}$ for 1 week and weighed again to determine the weight loss. The weight loss of the polymer films after hydrolysis was evaluated as the residual weight $(\%)$, which was defined by the Equation 2 (the average of three measurements was used in the calculations):

$$
\text { Residual Weight }(\%)=100-\left(\frac{w_{0}-w_{t}}{w_{0}} \times 100\right)
$$

where $w_{o}$ and $w_{t}$ were the initial weight and the weight at time $t$, respectively.

\section{Infrared spectroscopy (FTIR)}

Infrared spectra of PUs before and after hydrolytic degradation were collected in a FTIR, Perkin-Elmer, model Spectrum 1000 spectrophotometer. Measurements were carried out using the attenuated total reflectance (ATR) technique. PU films were pressured against a ZnSe crystal. Spectras were produced by transmitting the infrared radiation directly through the sample, 64 scans were collected with resolution of $4 \mathrm{~cm}^{-1}$.

\section{Wide angle $X$ ray scattering (WAXS)}

Wide angle $\mathrm{X}$ ray scattering (WAXS) analysis was performed by using a Philips, model PW1710 diffractometer operated with $\mathrm{CuK}_{\alpha}$ irradiation at a scan rate of $2^{\circ} 2 \theta / \mathrm{s}$ in the range of 5 to $60^{\circ}$. WAXS profiles of PUs were obtained before and after hydrolytic degradation.

\section{Scanning electron microscopy (SEM)}

A JEOL, model JSM-5410 field emission scanning electron microscope operated at $15 \mathrm{kV}$ was used to observe the surfaces and the fractured surface of the samples. The films were fractured in liquid nitrogen and coated with gold by sputtering.

\section{Cell origin, isolation, and culturing of adipose tissue-derived stem cell}

Human adipose tissue was obtained with informed consent from healthy patients who had liposuction surgery for esthetic reasons in the "Núcleo de cirurgia plástica" (Center of Plastic surgery) - Belo Horizonte, Minas Gerais, Brazil. This project was approved by the Ethics Committee of Federal University of Minas Gerais. No diabetes, hepatitis, metabolic diseases, or other systemic complications were reported for these donors. Isolation and culturing of adipose tissue-derived stem cell (hADSC) was performed as described by Zuk et al. ${ }^{[11]}$. To isolate hADSC, adipose tissues were washed with phosphate-buffered saline (PBS), and the extracellular matrix was digested with $0.075 \%$ type I collagenase for 2 hours to release the cellular fractions tissues and then centrifuged at 1,200 times for 10 minutes to obtain a pellet. The pellet was incubated for 2 days at $37{ }^{\circ} \mathrm{C} / 5 \% \mathrm{CO}_{2}$ in control medium (DMEM supplemented with $10 \%$ FBS, $100 \mathrm{U} \cdot \mathrm{mL}^{-1}$ penicillin, and $100 \mu \mathrm{g} . \mathrm{mL}^{-1}$ streptomycin). Following incubation, the tissue culture plates were washed to remove residual nonadherent cells and maintained at $37{ }^{\circ} \mathrm{C} 15 \% \mathrm{CO}_{2}$ in control medium. The stromal cells were then cultured for 7 to 10 days until they reached confluence. The cells were then harvested by digestion with $0.5 \mathrm{mmol} . \mathrm{L}^{-1}$ EDTA $/ 0.05 \%$ trypsin, centrifuged at $1200 \mathrm{rpm} / \mathrm{min}$ for 5 minutes, suspended in DMEM supplemented with $10 \%$ FBS, 100 U.mL ${ }^{-1}$ penicillin, $100 \mu \mathrm{g} \cdot \mathrm{mL}^{-1}$ streptomycin, and plated at a density of approximately $2 \times 10^{4}$ cells $/ \mathrm{cm}^{2}$. Cells were cultured to confluence before a second harvesting and replating procedure as described above. The final hADSCs used were taken at $4^{\text {th }}$ passage.

Table 1. Composition (wt.\%) of waterborne PUs.

\begin{tabular}{cccccccccc}
\hline & W(SS) & PCL & PCL & DMPA & IPDI & HZ & TEA & H 2 D & DBDLT \\
& & $\mathbf{1 2 5 0}$ & $\mathbf{2 0 0 0}$ & & & & & & \\
\hline PU-A & 62 & 20.12 & - & 1.63 & 12.55 & 0.77 & 1.23 & 63.70 & 0.34 \\
PU-B & 67 & 8.57 & 13.72 & 1.38 & 10.69 & 0.77 & 1.05 & 63.82 & 0.34 \\
PU-C & 72 & - & 23.92 & 1.21 & 9.32 & 0.67 & 0.91 & 63.97 & 0.34 \\
\hline
\end{tabular}




\section{Cellular viability}

For the cell culture studies, $2 \times 3 \times 1 \mathrm{~mm}$ films were cut and sterilized in UV light for 60 minutes. These PU samples were then gently deposited inside the cell culture. After 72 hours of incubation, hADSC viability was evaluated by MTT assay, based on the reduction of tetrazolium salt to formazan crystals by dehydrogenase present in living cells mitochondria. We left $200 \mu \mathrm{L}$ of culture medium in each well and added $60 \mu \mathrm{L}$ of stock solution of MTT (5 mg.mL ${ }^{-1}$ ). Two hours later, the cell morphology was analyzed by inverted optical microscopy and formazan salts were solubilized with $200 \mu \mathrm{L}$ of SDS $10 \% \mathrm{HCl}$. After incubation, for 18 hours, in a controlled $5 \% \mathrm{CO}_{2} 95 \%$ humidified incubator at $37{ }^{\circ} \mathrm{C}$, the optical density measurement was done at $595 \mathrm{~nm}^{[13]}$.

\section{Alkaline phosphatase activity}

Alkaline phosphatase production was evaluated by BCIP-NBT assay. This assay is based on a chromagenic reaction initiated by the cleavage of the phosphate group of BCIP by alkaline phosphatase present in the cells. This reaction produces a proton, which reduces NBT to an insoluble purple precipitate. Briefly, the supernatant of each well was removed and the cell layer was rinsed twice with PBS. Then, $200 \mu \mathrm{L}$ of BCIPNBT solution, prepared as manufacturer's protocol, was added to each well. After 2 hours of incubation, the cells were observed by optical microscopy and the insoluble purple precipitates were solubilized with $210 \mu \mathrm{L}$ of SDS $10 \% \mathrm{HCl}$ and incubated for 18 hours. The optical density measurement was done at $595 \mathrm{~nm}$. We used cultures without samples as control.

\section{Collagen secretion measurement}

Collagen production was analyzed by SIRCOL assay in supernatants of the cells cultures. This method is based on the selective binding property of the syrius-red dye to the [Gly-X-Y] tripeptide end sequence of mammalian collagen. The collagen present in the supernatant, precipitated by the dye, was solubilized and measured by an optical density analysis at $595 \mathrm{~nm}$. The amount of collagen was calculated based on a standard curve of previously known concentrations of type I collagen and their optical density measurement ${ }^{[14]}$. As control, we used cultures without samples.

\section{Results and Discussion}

\section{Hydrolytic and alkaline degradation tests}

The hydrolysis of PUs in phosphate-buffered saline solution at $37^{\circ} \mathrm{C}$ was studied by monitoring the changes in mass of the samples during the tests. Figure 1a shows the results of the hydrolytic degradation of the samples and indicate that the crystalline fraction (WAXS results will be discussed later) of the materials strongly influenced the degradation rate. Although having lower contents of soft hydrolysable segments, PU-A displayed higher rates of hydrolysis, mainly because of its amorphous structure that is highly assessable to water. On the other hand, PU-B and PU-C have a partially crystalline structure that restricts the penetration of water molecules towards breaking ester sites. Other possible explanation includes a decrease in hydrophilicity for polyurethanes having higher contents of more hydrophobic soft segments. Figure $1 \mathrm{~b}$ shows the hydrolysis of the samples performed in an alkaline environment. The degradation process of polyurethane in alkaline solution is based on the hydrolytic attack of ester bonds ${ }^{[15]}$. In this high-pH solution, the PCL crystallites are also promptly hydrolyzed and higher rates of hydrolysis (loss of mass) were observed for samples with higher soft segment contents (PU-B and PU-C).

\section{Infrared spectroscopy (FTIR)}

Typical infrared spectra of PU-A, PU-B and PU-C are shown in Figure 2 where the characteristic IR absorption bands of poly(esterurethane) are marked.

The primary amine stretching modes appear at $3600-3150 \mathrm{~cm}^{-1}$. The absorption band at about $\sim 3300 \mathrm{~cm}^{-1}$ corresponds to hydrogen bonded $-\mathrm{N}-\mathrm{H}$ group and absorption at $\sim 3500 \mathrm{~cm}^{-1}$ to nonbonded $-\mathrm{N}-\mathrm{H}$. The carbonyl group stretching vibrations, $\mathrm{C}=\mathrm{O}$, appear at $1760-1600 \mathrm{~cm}^{-1}$. A series of specific absorption bands are present within the $1760-1600 \mathrm{~cm}^{-1}$ broad band, such as the absorption band due to the ester bond from PCL soft segments and others associated with multiple interactions between urea and urethane bonds and $-\mathrm{N}-\mathrm{H}$ groups. IR bands at $\sim 1720, \sim 1700, \sim 1660, \sim 1630 \mathrm{~cm}^{-1}$ are assigned, respectively, to free urethane stretching band, hydrogen bonded urethane stretching band, free urea stretching band, hydrogen bonded urea stretching band. The secondary amide absorption, $>\mathrm{N}-\mathrm{H}$, appears at $1640-1540 \mathrm{~cm}^{-1}$. The band at $1150 \mathrm{~cm}^{-1}$ is assigned to the stretching of the $-\mathrm{C}-\mathrm{O}-\mathrm{C}-$ group $^{[15-19]}$.

FTIR spectra of PU-B after hydrolysis performed at $37^{\circ} \mathrm{C}$ in PBS are presented in Figure 3. The infrared spectra were normalized to the $1045 \mathrm{~cm}^{-1}$ band assigned to $\mathrm{O}-\mathrm{C}^{[20]}$.

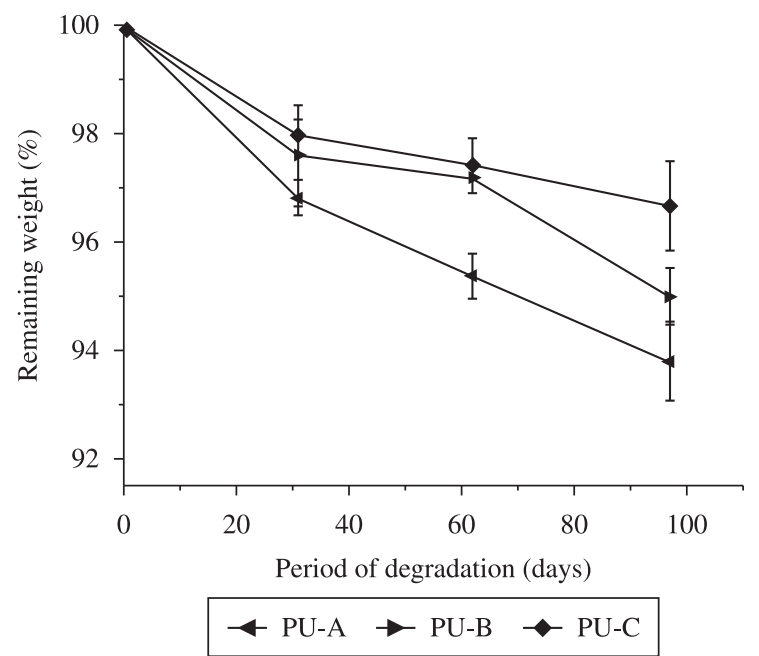

(a)

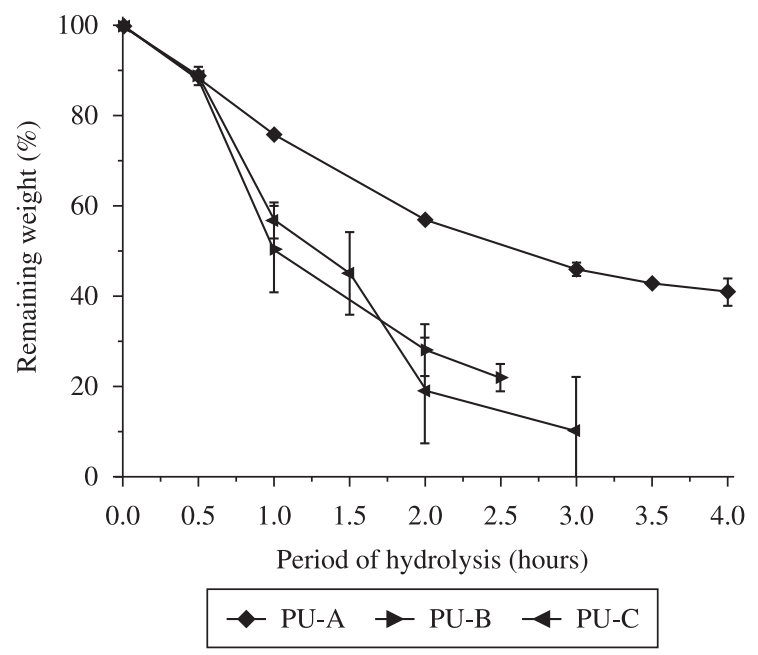

(b)

Figure 1. Mass changes of polyurethanes upon degradation in: a) PBS solution; and b) $\mathrm{NaOH}$ solution. 
Spectrum of the PU-B specimen after 97 days of incubation showed that peak intensities of bands at: $1295 \mathrm{~cm}^{-1}(v \mathrm{C}-\mathrm{N}+\delta \mathrm{N}-\mathrm{H}$, amide III), $1190 \mathrm{~cm}^{-1}(\mathrm{C}-\mathrm{O}-\mathrm{C} \text { of } \mathrm{C}(\mathrm{O})-\mathrm{O} \text {, ester, crystalline })^{[20]}$ and $934 \mathrm{~cm}^{-1}(\delta \mathrm{N}-\mathrm{H})$ increased compared with the original sample. On the other hand, the peak intensities of band $1160 \mathrm{~cm}^{-1}$ (vC-O-C, amorphous $)^{[21]}$ decreased. The shift in peak intensity of the ester band may indicate that the crystalline fraction increased during degradation.

The FTIR spectra in Figure 3 shows that the cleavage of urethane bonds takes place by: (i) the reduction in intensity of the $>\mathrm{N}-\mathrm{H}$ band, (ii) the increase in the intensity $-\mathrm{N}-\mathrm{H}$ band ${ }^{[22]}$.

The carbonyl region usually has been investigated for the quantitative study of microphase separation or mixing in PU. The extent of the carbonyl absorption groups participating in hydrogen bonding could be expressed by a hydrogen-bonding index $\mathrm{HBI}(\%)$, which is the fraction of hydrogen bonded in the carbonyl groups stretching vibrations Equation $3^{[9,10,15]}$. Since band overlapping is observed, a deconvolution mathematical procedure (by using the PickFiT $^{\circledast}$ software) was performed on spectra of Figure 1 to enhance resolution of carbonly.

$$
H B I(\%)=\frac{A_{1700}+A_{1640}}{A_{1700}+A_{1640}+A_{1724}+A_{1660}} \times 100
$$

where $A_{1724}, A_{1700}, A_{1660}$, and $A_{1640}$ are respectively the band peak area of free urethane, bonded urethane, free urea, bonded urea and ester.

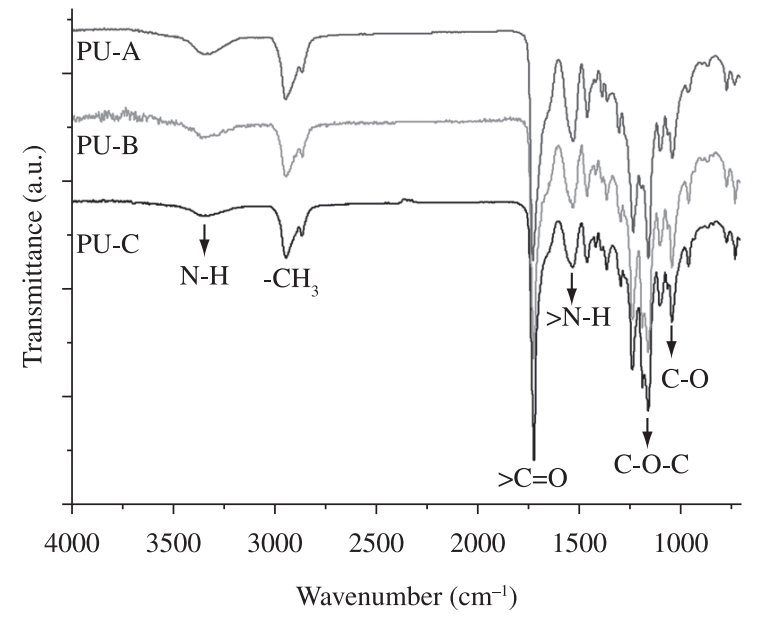

Figure 2. FTIR spectra of PU-A, PU-B and PU-C.

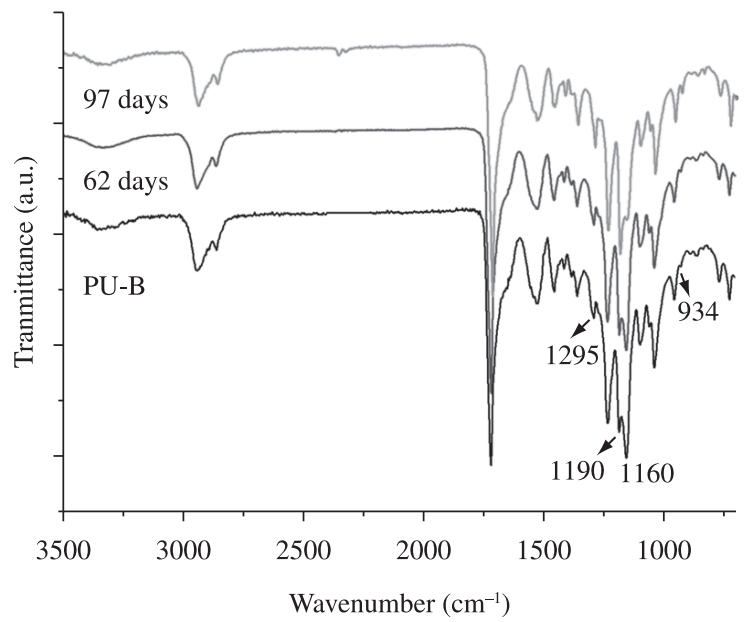

Figure 3. FTIR spectra of PU-B after hydrolysis performed at $37^{\circ} \mathrm{C}$ in PBS for 62 and 97 days.
HBI (\%) of PU-A and PU-C were investigated before degradation. PU-B was investigated before and after hydrolysis for 62 and 97 days. Figure 4 illustrates the deconvolution procedure used to determine the overlapped band of FTIR spectrum:

The values of HBI are shown in Figure 5 and indicate that the degradation process and also the annealing process that occurred at $37^{\circ} \mathrm{C}$ set conditions for the stabilization of a new phase separated

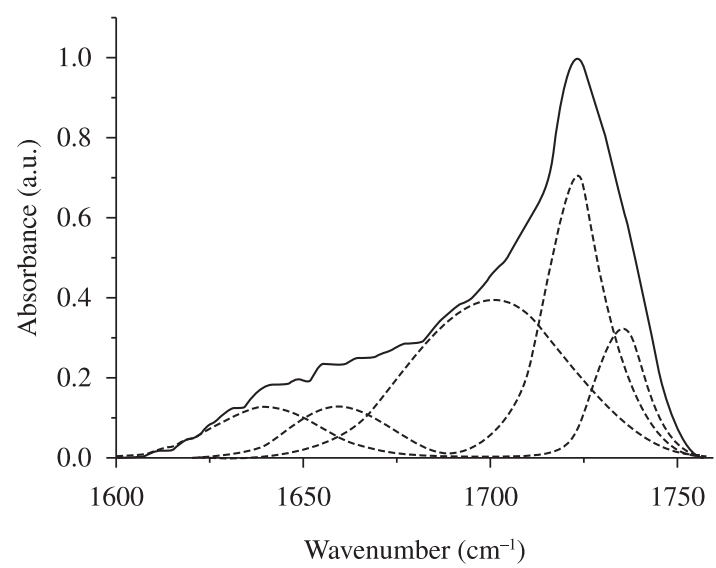

(a)

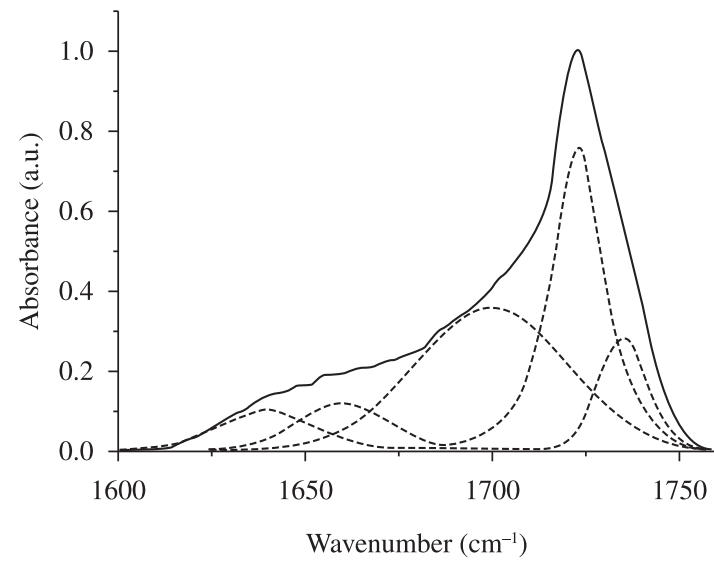

(b)

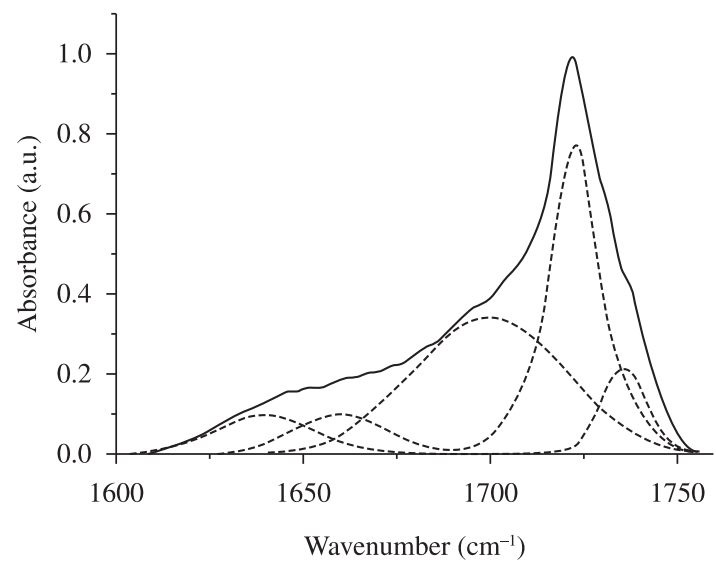

(c)

$$
\text { - Observed ---- Generated }
$$

Figure 4. Band area development of PU-B during hydrolysis performed at $37^{\circ} \mathrm{C}$ in $\mathrm{PBS}$. 
morphology. Chain cleavage and annealing can alter mobility and solubility and lead to higher contents of dissolved hard segments within the soft domains that would result in lower values of HBI.

\section{Wide angle $X$ ray scattering (WAXS)}

Figure 6 shows the WAXS profiles of PUs. The diffraction curves of PU-A, PU-B and PU-C show broad shoulders around $2 \theta=20^{\circ}$, which is typical of noncrystalline state with a characteristic short-scale order (interchain spacing) of $0.4-0.5 \mathrm{~nm}^{[17]}$.

Low molar mass PCL oligomers present in PU-A are less effective in adopting conformations that would result in crystallization of soft segments. On the other hand, as the soft segment content and the soft segment chain length increase (PU-B and PU-C), soft segments begin to be able to arrange themselves in more organized structures. The presence of these crystallites is detected as small sharp peaks in the PU-B diffraction pattern that become more distinct at PU-C curve, indicating that the soft segments are long enough to crystallize.

WAXS profiles of PUs after hydrolysis 62 days performed at $37{ }^{\circ} \mathrm{C}$ in PBS are presented in Figure 7. WAXS profiles of PUs are typical for semicrystalline polymers. Results indicated that the hydrogen-bonding structure of PUs is modified during the degradation process releasing the soft segments which allows them to crystallize. Moreover, the facilitated crystallization may be caused

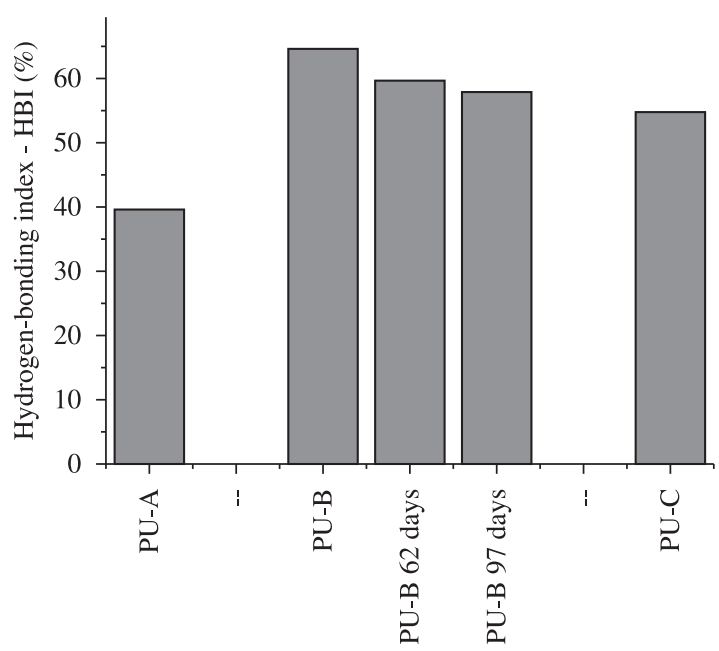

Figure 5. HBI (\%) of obtained PUs and degraded samples.

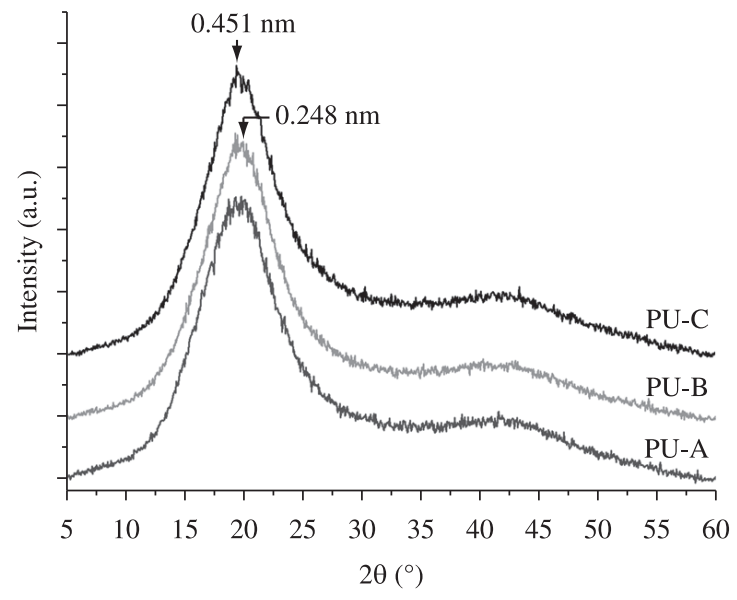

Figure 6. WAXS pattern of PU-A, PU-B and PU-C. by the test temperature, which may relate closely to the annealing thermal condition.

To investigate the crystalline structure of degraded PUs, the amorphous and crystalline parts were separated by a deconvolution procedure using the PickFiT ${ }^{\circledR}$ software. Gaussian curves were used to describe the amorphous phase and all the crystalline reflections, Figure 8 . The crystallinity index, $\alpha_{X}$, was defined as the ratio of the area under the separate crystalline pattern $\left(\sum A_{\text {crystalline }}\right)$ and the total scattering $\left(\sum A_{\text {crystalline }}+\sum A_{\text {amourphous }}\right)$ of the original pattern, ${ }^{[23]}$, Equation 4.

$$
\alpha_{X}=\frac{\sum A_{\text {crystalline }}}{\left(\sum A_{\text {crystalline }}+\sum A_{\text {amourphous }}\right)} \times 100
$$

As expected, the crystalline portion of PU-C, after degradation, is larger than PU-A or PU-B. PU-C has longer soft segment chains and longer chains are more likely to crystallize; once the bonds are broken, the chains become free to move and to organize in crystals. Crystals work as barrier to water diffusion decreasing the degradation rate, therefore, the hydrolytic degradation of PU-C is the slowest one. As observed at Table 2, the degradation kinetics of PU-B and PU-C are similar up to 62 days of degradation, afterwards, the degradation process of PU-B is accelerated compared to PU-C. Figure 9 shows WAXS results of PU-B and PU-C after hydrolysis, 97 days, performed at $37^{\circ} \mathrm{C}$ in PBS. The crystalline and amorphous

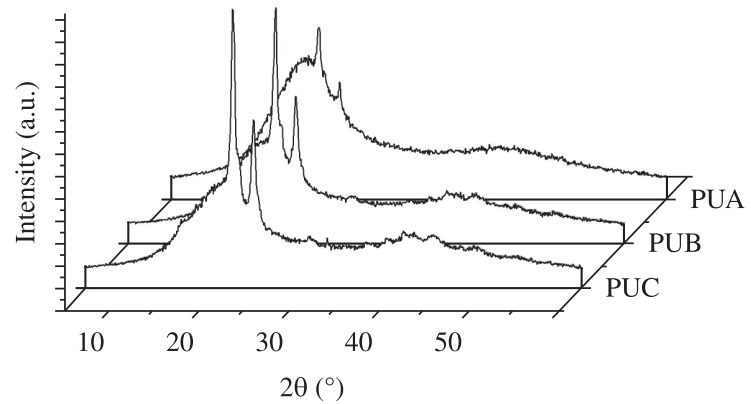

Figure 7. WAXS spectra of obtained PUs after 62 days hydrolysis performed at $37^{\circ} \mathrm{C}$ in PBS.

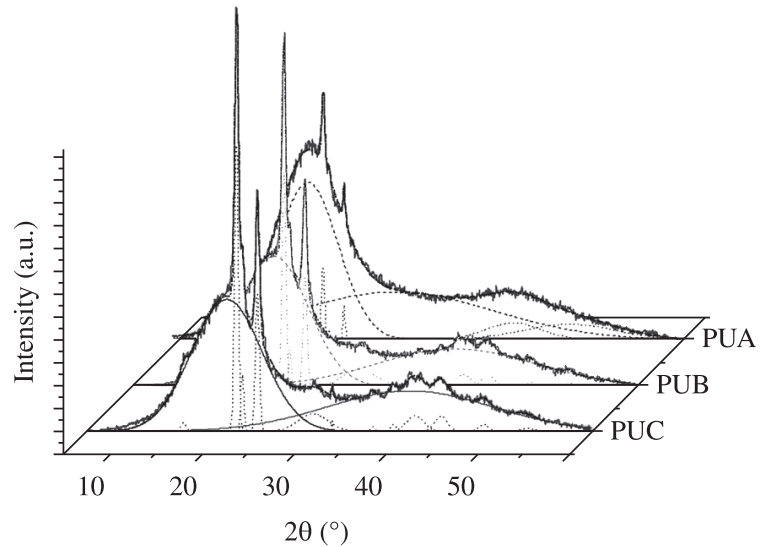

Figura 8. Peak deconvolution of the WAXS profiles: PU-A, PU-B and PU-C; after 62 days hydrolysis performed at $37^{\circ} \mathrm{C}$.

Table 2. Crystallinity index after hydrolysis performed at $37^{\circ} \mathrm{C}$ in PBS

\begin{tabular}{ccc}
\hline & 62 days & 97 days \\
\hline PU-A & $12.61 \%$ & NA \\
PU-B & $13.98 \%$ & $13.32 \%$ \\
PU-C & $16.28 \%$ & $17.51 \%$ \\
\hline
\end{tabular}

$\mathrm{NA}=$ not available 
portion of WAXS patterns were obtained according to Equation 4. Results indicate that the crystalline portion of PU-C increases during the degradation process while the crystalline portion of PU-B seems to stabilize, which might explain the slower degradation kinetics of PU-C. Results are summarized in Table 2.

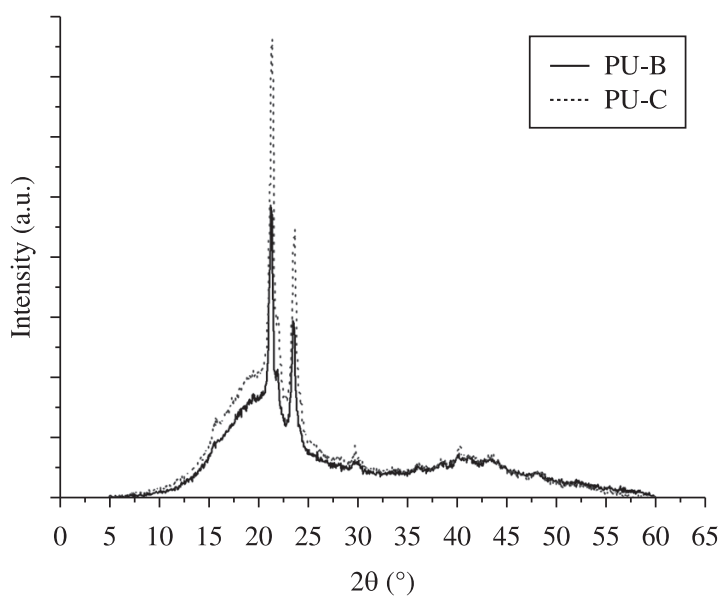

Figure 9. WAXS curves of PU-B and PU-C after 97 days hydrolysis performed at $37^{\circ} \mathrm{C}$ in PBS.

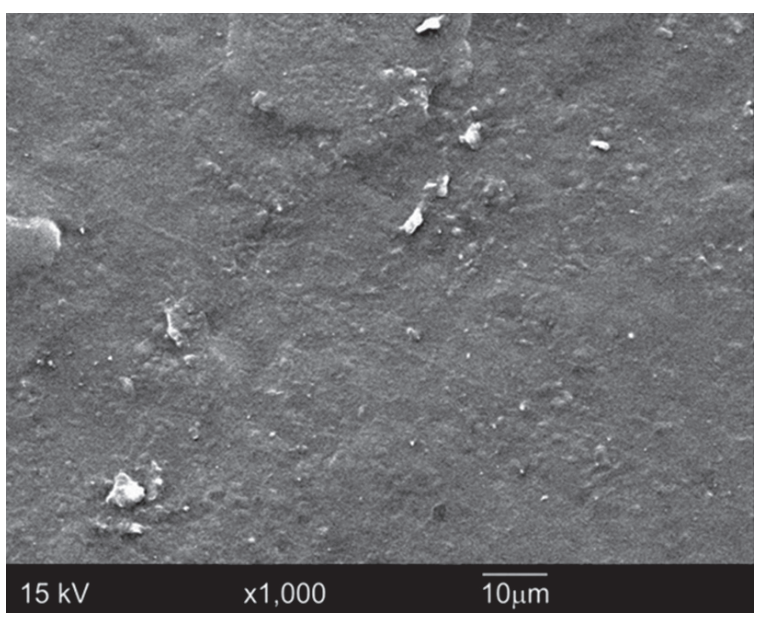

(a)

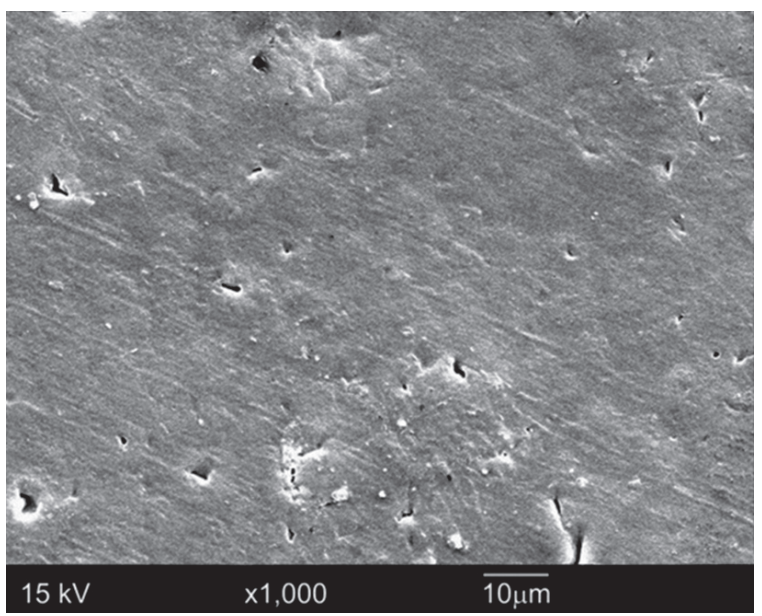

(c)

\section{Scanning electron microscopy (SEM)}

Figure 10 shows the surface morphology and fracture surface of PU-B after hydrolysis performed at $37{ }^{\circ} \mathrm{C}$ in PBS for 62 and 97 days. As the degradation proceeded, the surface became rugged and eroded. The fracture surfaces show that the degradation occurs from the surface to the bulk of the material, i.e., surface limited erosion. The rate of water diffusion through the sample should be lower than the rate of hydrolysis. The thickness of the damaged layer due to partial degradation can be used to monitor the evolution of the degradation process. In Figure 10b, for example, the thickness of the modified layer is $\sim 26 \mu \mathrm{m}$, while this value is increased to $\sim 79 \mu \mathrm{m}$ after 97 days (Figure 10d).

\section{Cellular viability}

Cellular viability studies performed by using MTT assay are presented in Figure 11a. This method measures the cytotoxicity, proliferation or activation because it detects only living cells and the signal generated is dependent on the degree of activation of the cells ${ }^{[24]}$. The assay showed that the cells were able to keep their activity when in contact with the produced polyurethanes. When compared to control, the optical density measurements of the solubilized formazan crystals showed a small increase in cell viability in the presence of PU-A and a decrease in PU-C. It is possible that the amorphous nature of PU-A and its slight higher

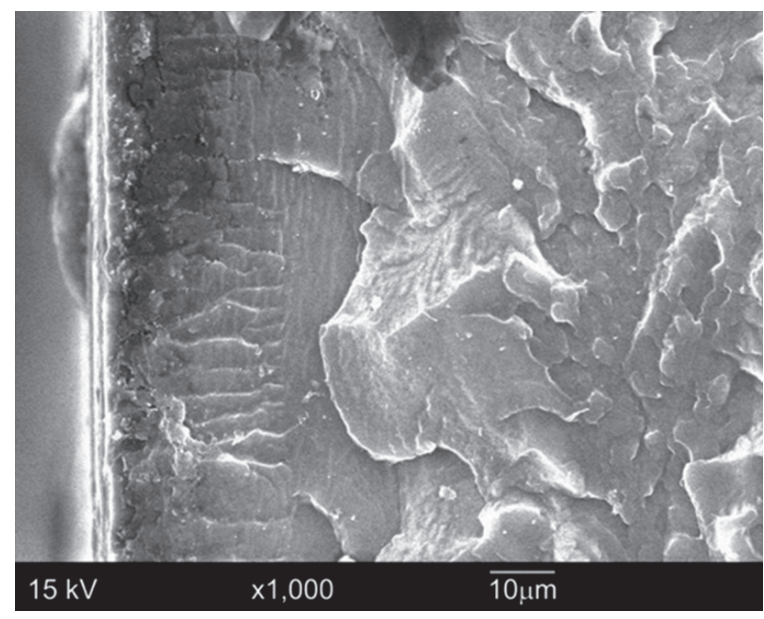

(b)

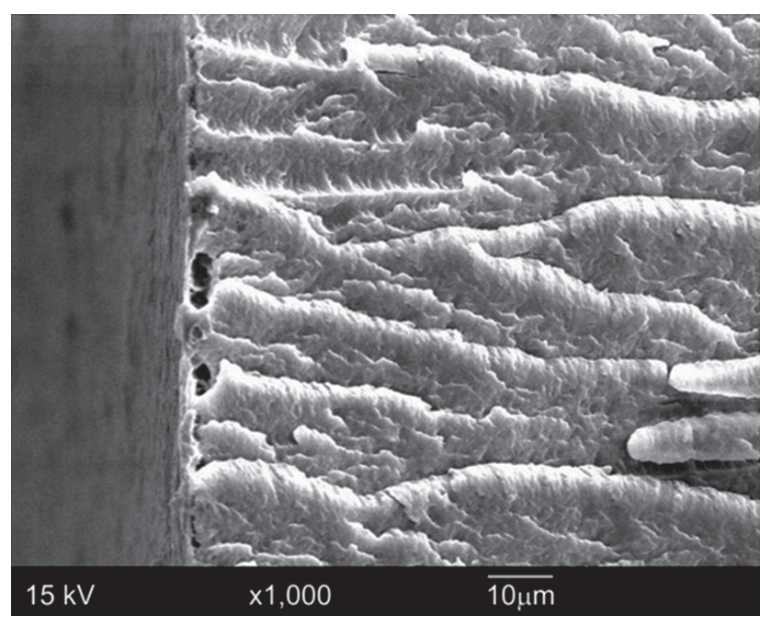

(d)

Figure 10. SEM images of PU-B sample degraded in PBS solution at $37^{\circ} \mathrm{C}$ : a) surface morphology after 62 days; b) fracture surface after 62 days; c) surface morphology after 97 days; and d) fracture surface after 97 days. 


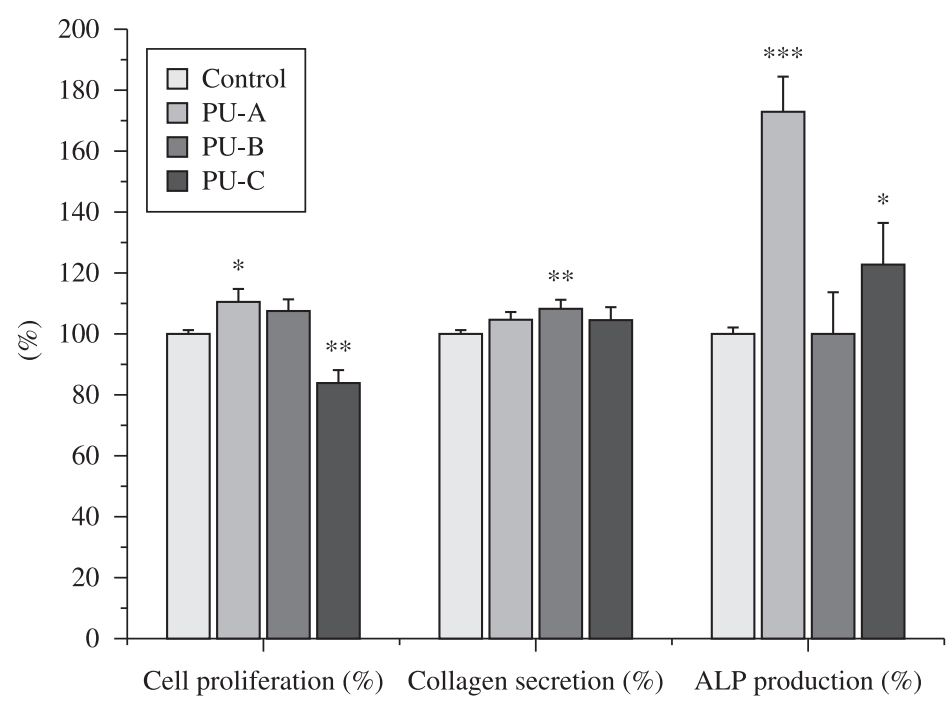

(a)

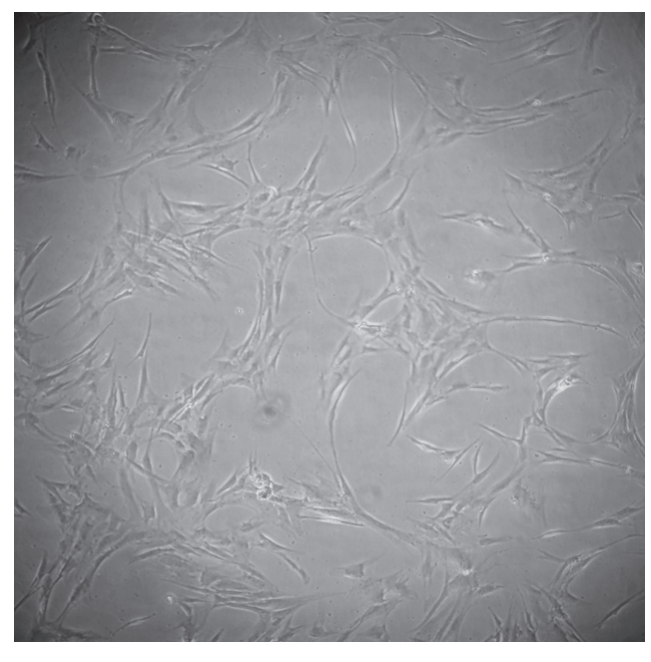

(b)

Figure 11. a) Cellular viability evaluated by MTT assay, collagen secretion by SIRCOL assay and alkaline phosphatase production evaluated by NBT-BCIP assay, results evaluated after 3 days of incubation, results represent Mean \pm SD of triplicates from 3 separate experiments $(\mathrm{p}<0.05),(*)$ indicates that there is a significant difference; and b) photomicrographs of hMSCs (150x) in contact with PU's.

hydrophobic characteristic can contribute to cell fixation and proliferation. The presence of PUs does not interfere significantly with collagen secretion. It was also observed that the alkaline phosphatase activity in the presence of the PU-A and PU-C was higher when compared with the control group, Figure 11a. Only normal cells can metabolize and be colored by BCIP-NBT as observed in the cells of the photomicrographs in Figure 11b.

The results suggest that the obtained PUs, particularly PU-A, support the viability and proliferation of hMSCs. MSCs are the natural precursor cells of cartilage tissue through chondrogenic differentiation into chondrocytes, which produce a cartilaginous matrix.

\section{Conclusion}

Hydrolysable polyurethanes having different PCL based soft segment contents were successfully produced by using water instead of organic solvents as the reaction environment. Soft segment content and the chain length were observed to affect the degree of hydrogen bonding and crystallinity. The obtained polyurethanes were hydrolysable in both PBS and alkaline solutions. The rate of hydrolysis was enhanced when alkaline conditions were used during the test. Moreover, the rate of hydrolysis was able to be tailored by altering the soft segment content of the polyurethanes. The obtained PUs are a promising material for cartilage repair, providing a good environment for the adhesion and proliferation of hMSCs.

\section{Acknowledgements}

The authors acknowledge the financial support from the following institutions: National Council for Scientific and Technological Development (CNPq) and the State of Minas Gerais Research Foundation (FAPEMIG).

\section{References}

1. Redman, S. N.; Oldfield, S. \& Archer, C. W. - Eur. Cell. Mater., p.2 (2005).

2. Buckwalter, J. A. - J. Orthop. \& Sport. Phy. Ther., 28, p.192 (2008).

3. Ratner, B. D.; Hoffmann, A. S.; Schoen, F. J.; Lemons, J. E. - "Biomaterials science: an introduction to biomaterials in medicine”, Elsevier (2004).

4. Nöth, U.; Tuli, R.; Osyczka, A. M.; Danielson, K. \& Tuan, R. S. - Tissue Eng., 8, p.131 (2002).
5. Martino, A. D.; Sittinger, M. \& Risbud, M. V. - Biomaterials, 26, p.5983 (2005). 6. Szycher, M. “Introduction. Szycher's Handbook of Polyurethanes”, CRC Press, London (1999).

7. Yang, J. H.; Chun, B. C.; Chung, Y. C. \& Cho, J. H. - Polymer, 44, p.3251 (2003).

8. Hong, J. H.; Jeon, H. J.; Yoo, J. H.; Yu, W. R. \& Youk, J. H. - Polym. Degrad. Stab., 92, p.1186 (2007).

9. Feng, Y. K. \& Li, C. Y. - Polym. Degrad. Stab., 91, p.1711 (2006).

10. Minnen, B. V.; Leeuwen, M. V.; Stegenga, B.; Zuidema, J.; Hissink, C. E.; Kooten, T. G. \& Bos, R. R. M. - Mater. Sci. Mater. Med., 16, p.221 (2005),

11. Zuk, P. A.; Zhu, M.; Ashjian, P.; Ugarte, D. A.; Huang, J. I.; Mizuno, H.; Alfonso, Z. C.; Fraser, J. K.; Benhaim, P. \& Hedrick, M. H. - Mol. Cell. Biol., 13, p.4279 (2002).

12. Awada, H. A.; Wickham, M. Q.; Leddy, H. A.; Gimble, J. M. \& Guilak, F. Biomaterials, 25, p.3211 (2004).

13. Amaral, M.; Costa, M. A.; Lopes, M. A.; Silva, R. F.; Santos, J. D. \& Fernandes, M. H. - Biomaterials, 23, p.4897 (2002).

14. Reinert, H. T. \& Jundt, J. - Histochem. Cell. Biol., 112, p. 271 (1999).

15. Ayres, E.; Oréfice, R. L. \& Yoshida, M. I. - Eur. Polym. J., 43, p.3510 (2007).

16. Chattopadhyay, D. K.; Sreedhar, B. \& Raju, K. V. S. N. - Polymer, 47, p.3814 (2006).

17. Kim, B. K.; Lee, S. Y. \& Xu, M. - Polyurethanes, 37, p.5781 (1996).

18. Marcos-Fernández, A.; Abraham, G. A.; Valentín, J. L. \& San Román, J. Polymer, 47, p.785 (2006).

19. Coates, J. P. - "A Practical Approach to the Interpretation of Infrared Spectra", in: Encyclopedia of Analytical Chemistry, p.10815, Meyers, R. A. Ed., Wiley, Chichester (2000).

20. Feng, Y. K. \& Li, C. Y. - Polym. Degrad. Stab., 91, p.1711 (2006).

21. Dillon, J. - "Infrared Spectroscopy Atlas of Polyurethanes (Including Model Compounds)", Technomic Lancaster, USA (1989).

22. Chew, M. Y. L.; Goh, S. H.; Kang, L. H.; Kang, L. H. \& Tan, N. - Build. Environ., 34, p.49 (1999).

23. Pompe, G.; Pohlers, A.; Pötschke, P. \& Pionteck, J. - Polymer, 39, p.5147 (1998).

24. Mosmann, T. J. - Immunol. Methods, 65, p.55 (1983).

Enviado: $25 / 02 / 10$

Reenviado: $25 / 04 / 10$

Aceito: $27 / 04 / 10$

DOI: $10.1590 /$ S0104-14282010005000040 